\title{
O Trabalho como Pena Alternativa: Análise de um Projeto para Cumpridores de Prestação de Serviço à Comunidade
}

\section{Work as Alternative Sentencing: Analysis of a Project for Court- Ordered Community Service}

\author{
Onair Zorzal Correia Junior', Vanessa Andrade de Barros²
}

\begin{abstract}
Resumo
Este artigo, realizado com base em um estudo empreendido com cumpridores de Prestação de Serviço à Comunidade (PSC) - modalidade de pena alternativa à prisão -, tem como objetivo investigar o sentido por eles atribuído a esse trabalho, identificado como penalidade. Os referenciais teórico-metodológico selecionados para a pesquisa foram a Psicossociologia do Trabalho e a Ergologia, acionados com a função de acompanhar um grupo de nove cumpridores de PSC em atividades desempenhadas em uma instituição na cidade de Santana do Paraíso, Minas Gerais. No que diz respeito aos resultados da pesquisa, concluiu-se que as atividades desempenhadas possibilitaram aos sujeitos a ressignificação da experiência de penalização e a construção de outras zonas de sentido para o trabalho. Emergiram ressalvas ao discurso de valorização da PSC, mediante o questionamento da penalização como garantia da não reincidência criminal. Dessa forma, sugere-se pensar em atividades de trabalho que estimulem amplamente a participação social e a valorização subjetiva.
\end{abstract}

Palavras-chave: Prestação de serviço à comunidade. Alternativas penais. Trabalho.

\begin{abstract}
Based on a study done with convicts sentenced to Community Service Order (CSO) - modality of sentencing alternative to imprisonment - this paper investigates the meaning attributed by these convicts to this work, identified as a punishment. The theoretical-methodological references selected for the research were Work Psychosociology and Ergology, with the objective of accompanying a group of 9 CSO doers in activities performed at an institution in the city of Santana do Paraíso, MG, Brazil. Regarding the results of the research, it was concluded that the activity enabled the subjects to re-signify the experience of punishment and the construction of other dimensions of meaning for the work. Caveats to the defense of CSOs appeared and there was questioning of whether or not punishment could ensure no repeat offences. In this way, we suggest thinking about work activities that encourage social participation and subjective recognition.
\end{abstract}

Keywords: Community service order. Sentencing alternatives. Work.

\footnotetext{
${ }^{1}$ Faculdade Pitágoras de Ipatinga, Ipatinga, Brasil. E-mail: onairzorzal@gmail.com.

${ }^{2}$ Universidade Federal de Minas Gerais, Belo Horizonte, Brasil. E-mail: vanessa.abarros@gmail.com.
} 



\section{Introdução}

Neste artigo será discutida a utilização do trabalho no sistema penal, especificamente a Prestação de Serviço à Comunidade (PSC), modalidade tratada como substitutiva ao sistema prisional, logo, inserida na categoria de penas alternativas de cumprimento em liberdade. O objetivo é investigar os sentidos da pena de PSC para os cumpridores, assim como a ressonância dessa condição sui generis de trabalho em seus cotidianos, nos âmbitos pessoal, coletivo e histórico de suas vidas.

\section{Do trabalho como pena à prestação de serviço à comunidade}

Segundo Rusche e Kirchheimer (2004, p. 21), "todo sistema de produção tende a descobrir formas punitivas que correspondem às suas relações de produção". Essa assertiva aponta para a impossibilidade de analisar o sistema penal sem ponderar sobre o sistema produtivo, a economia e o capital, visto que, nas diversas modalidades penais sustentadas ao longo dos séculos, o trabalho foi utilizado como estratégia de domínio dos corpos dos desviantes (Foucault, 2009).

Como exemplos, vejam-se práticas punitivas no século $\mathrm{XV}$, como o trabalho nas galés, embarcações esguias movidas a remo por condenados (Braga, 1999), e o desterro, prática de deportação de criminosos, marcada pela expulsão e criação de mão de obra nas colônias americanas. Entre os séculos XVIII e XIX, destacam-se, segundo Melossi e Pavarini (2006), as casas de correção e as casas de trabalho, espaços com função de disciplinar e ensinar ofícios para o trabalho, que tinham como um dos objetivos a formação para o trabalho dos desempregados advindos do sistema feudal. Destaca-se igualmente a operacionalização do ambiente fabril do sistema penitenciário americano surgido no século XIX, constituído por dois modelos Filadélfia e Auburn -, que tentavam, cada qual em sua medida, responder a duas questões: "encontrar um sistema econômico de administração, ou aumentar a produtividade do trabalho institucional" (Melossi \& Pavarini, 2006, p. 186).

Frente a tal cenário histórico, torna-se importante compreender como o atual modelo econômico se relaciona às práticas punitivas contemporâneas.

Partimos do ponto de vista de que, na atualidade, o consumo e a descartabilidade dos produtos configuram-se como o plano de ação principal que orienta também as relações de vida e de trabalho (Neves, 1997). De fato, os trabalhadores representam uma massa poliforme de homens e mulheres, cuja força de trabalho é utilizada de múltiplas formas, para além do proletariado fabril: trabalhadores de setores informais; terceirizados; incorporados a setores de serviço; do Terceiro Setor, que trabalham em seus domicílios ou em multinacionais (Antunes \& Alves, 2004). Contudo, a ampliação das formas de utilização da força de trabalho não resultou em melhorias no acesso da população a melhores condições de trabalho. O que se encontra é uma multidão - particularmente constituída de jovens, mulheres, idosos, negros, moradores de periferia e pessoas de baixa escolaridade - em situação de extrema precariedade profissional, isto é, diante da dura realidade de que não faz, e talvez nunca fará, parte do mundo do trabalho formal (Barros \& Carreteiro, 2011). 
Acreditava-se que, com as novas tecnologias, a prisão, em sua função de tornar os corpos dóceis e produtivos ao sistema fabril (Foucault, 2009) e obter lucro com a utilização de um mercado cativo de mão de obra barata, estaria fadada a ter fim; todavia, nas últimas décadas, ela ganhou um status diferenciado, não sendo mais necessária para se obter lucro, pois ela é o próprio lucro. Isso se expressa claramente na privatização do sistema prisional, com a terceirização de serviços contratados inclusive com os Estados, que passam a pagar por vagas ocupadas. Assim, atualmente, muitos estabelecimentos prisionais são geridos quase que exclusivamente por empresas privadas (Wacquant, 1999). Como consequência, o trabalho no sistema prisional passa a prescindir da mão de obra dos reclusos para a obtenção do lucro - visto que o que é disponibilizado como trabalho não é capaz de contemplar todos os detentos - e ganha a função de diminuir os gastos com o sistema prisional, ou, ainda, apresenta-se como estratégia de controle dos presos, já que grandes empresas os colocam na realização de atividades simplificadas mediante remuneração irrisória, da qual serão descontados quase " $80 \%$ [...] na forma de impostos, indenização à vítima ou taxas judiciais" (Jinkings, 2013, p. 86).

Conforme Bitencourt (1999, p. XXIII), "a pena privativa de liberdade, que atingiu seu apogeu na segunda metade do século XIX, começou a enfrentar sua decadência antes mesmo que esse século terminasse". Essa constatação subsidia o entendimento de que a prisão é um meio extremo de crueldade e que deveria ser repensada com a criação de meios alternativos de reeducação, principalmente para as penas de curta duração.
Seguindo o panorama de críticas ao sistema penal, encontra-se no âmbito internacional a criação da Declaração Universal dos Direitos Humanos, de 1948, primeiro gesto no sentido da construção de um embasamento sobre o valor da liberdade, da justiça e da paz. Posteriormente, uma série de encontros realizados pela Organização das Nações Unidas (ONU) culminou na criação deste que passou a ser o documento mais expressivo no que tange às penas alternativas - as Regras Mínimas para a Elaboração de Medidas Não Privativas de Liberdade, conhecidas como Regras de Tóquio, estabelecidas em 1990 (Ilanud, 2006). Seu conteúdo estabelece para os Estados-membros a utilização de meios não privativos de liberdade, ressaltando a participação da comunidade na execução das penas judiciais. Para tanto, argumenta a favor de uma política penal menos punitiva e da economia do Judiciário, pautandose sempre pelos direitos humanos, pela justiça social e pela reinserção do sentenciado (Ministério da Justiça, 1998).

No Brasil, o surgimento das penas restritivas de direito, que correspondem às penas alternativas, datam do ano de 1984, a partir da modificação da Lei nº 7.209/84 do Código Penal Brasileiro, sendo que uma série de outras leis foram a ele acopladas, legitimando o uso de outros dispositivos diferentes da prisão. Entretanto, mesmo com a presença das penas restritivas de direito no ordenamento jurídico, não havia, inicialmente, uma política que garantisse a efetividade de sua aplicação, o que as colocou em descrédito no Poder Judiciário, visto que inexistia qualquer aparato de acompanhamento dos sujeitos em cumprimento de pena. Contava-se, no máximo, com a aplicação 
de penas pecuniárias, uma modalidade de pena cumprida mediante pagamento de um valor estabelecido em audiência (Albernaz \& Sá e Silva, 2009).

Com a criação da Central Nacional de Acompanhamento às Penas e Medidas Alternativas (Cenapa), em 2000, traçam-se como metas o fomento e a criação de dispositivos que poderiam fazer o acompanhamento dos penalizados: Centrais de Acompanhamento de Penas e Medidas Alternativas (Ceapa), que possibilitariam estratégias para aplicação de penas alternativas à prisão em todo o território nacional. Os esforços iniciais se concentraram na busca de credibilidade para a aplicação dessas penas alternativas pelos magistrados, sendo que, de início, a superação da ideia de impunidade que pairava sobre elas era a tarefa mais árdua (Barreto, 2006).

Tal impulso significou mudança na aplicação penal: de quatro varas especializadas em penas e medidas alternativas e 26 centrais/núcleos, em 2002, para 20 varas e 389 núcleos em 2009, o que influenciou diretamente no número de pessoas acompanhadas e monitoradas. Já no primeiro semestre de 2008, essas penas, com um número de 493.737 execuções, ultrapassaram as penas privativas de liberdade, com 498.729 pessoas presas.

De acordo com Souza (2014), uma relevante questão que tem permeado as discussões sobre as penas alternativas relacionase à efetivação de sua função de desencarceramento. Esse autor indica que é necessário refletir se as penas têm conseguido efetivar-se baseadas em uma proposta de descriminalização ou se, ao contrário, têm criminalizado infrações que até então não estariam sendo punidas em outras instâncias. Segundo dados advindos do Infopen (Ministério da Justiça e Segurança Pública, 2017), o aprisionamento tem aumentado exponencialmente, posicionando o Brasil em terceiro lugar no ranking de pessoas presas, com um total de 726.712 até junho de 2016, ficando atrás somente dos Estados Unidos e da China. Nesse sentido, tratar as penas alternativas como distanciadas do discurso que remete ao aprisionamento é uma tarefa complexa que precisa ser analisada com mais cuidado (Karam, 2010; Souza, 2014).

Souza (2014) buscou compreender quais condições discursivas têm promovido a política de alternativas penais. $\mathrm{O}$ autor sinaliza que, após a criação do Código Penal de 1984, percebe-se a articulação de mudanças em prol de leis mais punitivas, tanto no que se refere a um maior rigor para crimes já existentes como a um incremento de normas penais que anteriormente não eram vinculadas ao Estado, caracterizando o Direito Penal como resposta à maior parte dos conflitos sociais. Souza complementa que, paralelo a esse modelo mais repressivo, havia uma militância em favor da produção "de uma política criminal alternativa, [...] por meio da despenalização" ou "pela ampliação das hipóteses de aplicação de alternativas penais à prisão” (2004, p. 21).

Mediadas por relações de "poder-saber", na esteira de Foucault, as alternativas penais devem ser vislumbradas em sua polimorfia, dentro de um jogo político orientado por contextos que a apregoam com significados diferenciados.

No Brasil, segundo estudo realizado pelo Instituto Latino-Americano das Nações Unidas para Prevenção do Delito e Tratamento do 
Delinquente (Ilanud, 2006), a PSC - Prestação de Serviços à Comunidade - tem prevalência no sistema judiciário, principalmente quando comparada à segunda forma mais utilizada - a pena pecuniária. Nesse sentido, a primeira figura como a alternativa que reagiria ao imaginário social da impunidade e como a prática mais dotada de potencial socializante para aquele que a cumpre, visto que promove uma aproximação dos condenados com a comunidade no contexto de cumprimento da pena (Oliveira, 2009). Além disso, remete à reparação da sociedade e à responsabilização subjetiva daqueles que cometeram os atos ilícitos por meio de uma função específica: o trabalho.

Quais benefícios as instituições recebem quando acolhem pessoas para o cumprimento de PSC? Inicialmente, a resposta para essa pergunta está nas prerrogativas penais, em que se prevê a obrigatoriedade de as instituições de interesse público se colocarem à disposição para receberem cumpridores, o que estaria enraizado em seu compromisso com a cidadania. Caberia, pois, aos movimentos e às instituições de cunho social a promoção da inserção e da participação dos sujeitos penalizados na coletividade.

A comunidade é tomada como espaço essencial para as ações de reinclusão social, sendo, por si só, portadora de uma função educativa, visto ser o ambiente capaz de reensinar o sujeito a viver em sociedade, para que não venha a reincidir em práticas delitivas (Rosemblant, 2014). Nessa lógica, a intervenção comunitária, ampliada por uma alta valorização, teria o papel de modular os sujeitos de forma que os valores de solidariedade e cidadania, característicos das instituições de razão social, pudessem ser incutidos naqueles que cumprem pena (Rosemblant, 2014).

Tal posição é problemática, na medida em que desconsidera o lugar da alteridade no processo penal, deslegitimando o sujeito de sua construção psíquica e social, analisando-o pela via da individualidade e descartando as questões sociais e históricas que o compõem. As próprias dificuldades vividas pelas instituições dessa natureza demonstram que estas, em sua maioria, trabalham de forma precária, financiadas essencialmente pelo Estado ou por fundos privados, sem conseguirem a garantia de continuidade de suas ações (Yamamoto, 2007; Paiva \& Yamamoto, 2008). Em virtude disso, a apresentação de cumpridores de penas alternativas, no contexto de uma criminologia midiática de cunho repressivo, é percebida como mais um problema encaminhado pelo Estado.

O criminoso estigmatizado e antes vinculado somente ao sistema prisional agora chega à liberdade, e mais do que isso, vincula-se às instituições sociais da própria comunidade. Augusto (2010) recorre aos argumentos de Deleuze e Passetti sobre a construção da sociedade de controle, que reorganiza e flexibiliza estratégias de organização social para além dos dispositivos disciplinares. Assim, na esfera penal, o controle, combinado à disciplina, revela-se o movimento praticado pelos agenciamentos de poder da sociedade capitalista, relegando as classes desprivilegiadas (precisamente as que deveriam ser mais protegidas) a um constante monitoramento. Conforme Deleuze (1992) argumenta, "no capitalismo só uma coisa é universal, o mercado", e, por meio dele, semeiamse os frutos da pobreza e da miséria entre as massas, organizadas em uma lógica social "que 
funciona não mais por confinamento, mas por controle contínuo e comunicação instantânea" (p. 213-216).

Por isso, a comparação das periferias a "campos de concentração a céu aberto" (Augusto, 2010, p. 178) mediante as diversas instituições privadas ou do Terceiro Setor que exercem função de políticas sociais, mas que têm como alvos jovens considerados infratores. Na lógica de uma sociedade de controle, novos atores são convocados para além da polícia, da prisão e do delinquente. As instituições sociais colocadas como possibilidades de resposta às deslegitimidades advindas do sistema penal corroboram com a aproximação cada vez maior entre o universo prisional e a vivência comunitária. Se antes o problema estava apenas em uma ordem biopolítica de cerceamento dos sujeitos em determinadas instituições, hoje, as práticas denominadas democráticas são visadas como estratégias de controle para a manutenção dos habitantes da periferia em um plano sem muros (Augusto, 2010; Deleuze, 1992).

\section{O percurso metodológico}

Descrever uma pesquisa é como narrar uma história dotada de encontros, vínculos, dramas e acontecimentos inesperados, afinal, por maior que seja o planejamento, nunca será possível prever todos os rumos que ela tomará, uma vez que o pesquisador está sempre em processo de tensão entre a limitação de seu próprio conhecimento e as imprevisibilidades do mundo real (Goldenberg, 2009; Feyerabend, 2011). A orientação teórico-metodológica que embasa esta pesquisa é constituída pelas chamadas clinicas do trabalho, em especial a
Ergologia e a Psicossociologia do Trabalho (Bendassolli \& Soboll, 2011). Conforme afirma Cunha (2014), ambas as clínicas têm pontos que as unem no desvelamento do trabalho real e do lugar que ele ocupa na construção tanto subjetiva quanto concreta na vida dos trabalhadores. Trabalhar diz respeito a um engajamento do próprio sujeito que trabalha, com a realidade que é transformada e a expectativa dos outros (Lhuilier, 2009). Para Lhuilier, (2005, p. 212) trabalho é "o palco onde atuam simultânea e dialeticamente a relação consigo próprio, a relação com outro e a relação com o real”. Sendo assim, a autora afirma que encontrar um sentido para o trabalho é "daí retirar um duplo reconhecimento, simultaneamente aos seus próprios olhos (em termos de imagem de si) e aos olhos dos outros" (Lhuilier, 2005, p. 212).

A Ergologia, apresenta uma construção empreendida pelos "processos socráticos em duplo sentido, entre os saberes constituídos e os saberes investidos, organizados no seio de um dispositivo dinâmico de três polos" (Trinquet, 2010, p. 94). No entendimento da Ergologia, torna-se possível discutir na atividade de trabalho como o sujeito transforma o que é prescrito, transgredindo a norma por meio do uso de si, gerando uma renormalização que garantirá o que realmente é realizado, praticado, real. Nesse sentido, falar de processos socráticos é apresentar um modelo que não se assume somente na construção dos especialistas que questionam (saberes constituídos), mas também na possibilidade de participação de quem de fato executa a atividade e a questiona (saberes investidos). Assim é que, em uma posição ergológica, encontramos os três polos de trabalho: o dos saberes constituídos, o dos saberes 
investidos e o polo ergológico, em que se dá a dialética existente entre os dois outros em uma posição de igualdade de saberes (Schwartz, 2011; Trinquet, 2010).

No âmbito da Psicossociologia, entendese a atividade de trabalho como algo estritamente mutável, à luz da pluralidade social, apresentada na complexidade das diversas dimensões que afetam os sujeitos de pesquisa (Barros \& Carreteiro, 2011). Para Lhuilier (2014, p. 6), “a psicossociologia oferece um conjunto de recursos essenciais para os campos da investigação e da ação, constituído pela articulação entre campo social, condutas humanas e vida psíquica". Nessa lógica, a construção do sujeito é entendida pelo laço existente entre a construção psíquica e a construção social, e deve-se estar alerta para a impossibilidade de subtração de uma dessas instâncias, visto que ambas se coadunam nas dinâmicas conscientes e inconscientes presentes na aproximação do sujeito com o outro e com o meio.

O processo desta pesquisa nasceu como um desejo de compreender as situações reais de trabalho, vislumbrando como estas são percebidas pelos sujeitos e incidem sobre eles. Como sugere Lima (2002, p. 124), “em vez de impormos nossa lógica a esse objeto, devemos tentar desvendar sua própria lógica". Tal escolha teórica e metodológica exigiu a imersão em campo como parte essencial da pesquisa, por meio da observação participante das dinâmicas sociais e ideológicas presentes nas relações estabelecidas no campo empírico, visto que os sujeitos, dotados de "autonomia e poder de ação" (Lhuilier, 2014, p. 7), constroem a realidade junto com o pesquisador que ali se debruça em implicação (Lhuilier, 2014).
Realizou-se a pesquisa no Instituto de Desenvolvimento Educacional de Integração Ambiental e Social (Ideias), uma organização não governamental sem fins lucrativos, norteada pelos princípios da educação ambiental e que promove ações que incidem sobre a mobilização e a participação social dos moradores do bairro Industrial, no município de Santana do Paraíso, em Minas Gerais (MG). Na época da pesquisa, o Ideias trabalhava com um projeto central intitulado "Cidadania dá em árvore?", que atuava em três frentes: recolhimento de material reciclável; acompanhamento de crianças e jovens da comunidade em oficinas de criação de brinquedos a partir desse material; e produção de brinquedos por cumpridores de PSC para doação a outras instituições. $\mathrm{O}$ nome do projeto era uma provocação ao uso indiscriminado dos recursos naturais, buscando questionar as noções capitalistas de consumo e descartabilidade. Financiado pelo recurso das penas pecuniárias, advindo de um fundo criado por meio da Resolução no 154/12 do Conselho Nacional de Justiça (CNJ), o projeto foi aprovado em edital lançado pela Vara de Execuções Penais da comarca de Ipatinga/MG. O encaminhamento dos cumpridores para a instituição era realizado pelo programa Central de Acompanhamento de Penas e Medidas Alternativas (Ceapa) da comarca de Ipatinga, que inclui moradores dos municípios de Ipatinga, Santana do Paraíso e Ipaba submetidos à pena de PSC pela Vara de Execuções Penais e Juizado Especial Criminal. Durante a pesquisa, nove pessoas cumpriram pena, construindo brinquedos pedagógicos com restos de madeira colhidos em marcenarias da região. As atividades realizadas consistiam em lixar e pintar as peças disponibilizadas pelo 
coordenador da instituição, sendo que os brinquedos depois eram destinados a instituições sociais como escolas e creches, dentre outras.

Buscando mais aproximação com a atividade e com os sujeitos cumpridores de PSC, optamos por realizar, na instituição, as mesmas tarefas desenvolvidas por eles, o que proporcionou uma aproximação da cultura e dos costumes da comunidade, assim como de suas histórias e de suas formas particulares de comunicação (expressões e gírias cotidianas). Realizamos tais atividades durante aproximadamente cinco meses, uma vez por semana, e as observações e impressões dessa etapa foram registradas em um diário de campo.

Com o estabelecimento de vínculos de confiança com os trabalhadores e a familiarização com as atividades ali desenvolvidas, as entrevistas foram iniciadas. Realizamos quatro entrevistas (Jonas, Atílio, Felipe e Cássia) ${ }^{3}$, que foram gravadas e transcritas. Os locais dos encontros foram escolhidos pelos próprios entrevistados, sendo que os três homens escolheram suas casas e a mulher escolheu uma praça próxima ao lugar onde trabalhava. Todos assinaram o Termo de Consentimento Livre e Esclarecido, em que aceitavam participar da pesquisa e autorizavam a utilização de um gravador.

Originalmente, planejou-se entrevistar todos os nove participantes da oficina, o que não foi possível. Entende-se, contudo, que essas "não entrevistas" dizem respeito à própria dinâmica das penas alternativas e seus contextos, especialmente as medidas de PSC. Segundo

\footnotetext{
${ }^{3}$ De maneira a preservar sua identidade e privacidade, todos os sujeitos receberam nomes fictícios, em conformidade com as normas do Comitê de Ética em Pesquisa. Além disso, a fim de preservar a máxima
}

Zaffaroni (2013), no campo da criminologia, existem palavras que não são ditas porque não são ouvidas ou porque não são passíveis de serem ouvidas: "as palavras dos mortos [...] falam-nos a partir de seu mutismo e às vezes são demasiadamente eloquentes" (p. 28).

Nesse sentido, os cinco sujeitos não entrevistados e os motivos de sua ausência na pesquisa foram: Alexandre - durante $\mathrm{O}$ cumprimento da PSC, foi reencaminhado para cumprir a pena em outra instituição, devido à sua vinculação com a criminalidade; Graça encerrou o cumprimento da pena e mudou-se de cidade; Juliana - era muito faltosa às atividades, sendo que nos últimos meses não manteve contato com a instituição; Cristiano - foi preso por tráfico de drogas; Omar - foi morto próximo de sua casa por arma de fogo.

A construção teórica, assim como o processo de escrita, deu-se de forma entrelaçada ao caminhar no campo pesquisado e ao contato com as experiências observadas. Nesse sentido, não se almejou construir uma categorização enrijecida em busca de padrões que viessem elucidar uma determinada problemática, mas a construção de um saber pautado pela práxis existente na atividade pesquisada (Alves-Mazzoti, 2000; Vasquez, 1977). Rabelo (2014, p. 54) sublinha que "a subjetividade do pesquisador e as condições em que pesquisador e sujeitos de pesquisa se encontram não estão desatreladas das interpretações que se constroem. Por isso, os discursos não podem ser analisados como exteriores aos atores que os produziram”. Dessa

fidedignidade dos depoimentos, a transcrição da oralidade não passou por uma revisão gramatical, sendo que as intervenções se restringem à pontuação, necessária para apreensão do sentido pelo leitor. 
forma, as análises apresentadas neste texto têm alicerce em um processo de implicação que leva em consideração o processo de ressonância advinda da relação existente entre o pesquisador e os sujeitos pesquisados (Amado, 2005), em uma atitude contrária a qualquer posição de neutralidade científica.

\section{Discussão e análise: o trabalho como pena alternativa}

A pesquisa buscou promover uma análise sobre o trabalho executado por cumpridores da pena de Prestação de Serviço à Comunidade. A instituição onde se desenvolveu a pesquisa oferecia como trabalho a confecção de brinquedos feitos com material reciclável pelos cumpridores e doação desse artesanato para outras instituições.

Para os cumpridores de PSC na comarca em que se realizou esta pesquisa, ter uma atividade direcionada era algo novo, já que nenhuma instituição antes do Ideias havia utilizado o dinheiro das penas pecuniárias para promover o trabalho dos cumpridores. $\mathrm{Na}$ maior parte das vezes, o valor é utilizado para a aquisição de bens e outras benfeitorias nas instituições. No que diz respeito ao trabalho, geralmente, as instituições dão preferência a atividades cotidianas tidas como simples, tais como limpeza, arrumação, ou que necessitam de esforço físico, como auxílio em tarefas de construção (Correia Junior, 2016). Além disso, enquanto umas sugerem o não contato dos cumpridores com o público atendido, outras o permitem por atribuir aos trabalhadores a condição de voluntários.

O Ideias começou a receber cumpridores de PSC no ano de 2010. No início, eles auxiliavam em diversas tarefas, como nas oficinas com crianças, na coleta seletiva de lixo e na construção do espaço físico da instituição. Os cumpridores eram essenciais para a manutenção das atividades, pois sua mão de obra viabilizava o andamento de grande parte delas.

A aprovação do projeto "Cidadania dá em árvore?" permitiu a obtenção de recursos e operacionalização das atividades executadas pela instituição, o que deu à PSC um rumo diferenciado, em que os cumpridores passaram a atuar diretamente em um projeto desenvolvido exclusivamente para eles. Cada participante pintava um certo número de peças para a construção de brinquedos pedagógicos, não existindo uma delimitação prévia da quantidade de peças a serem pintadas por dia ou hora. Contudo, percebia-se que cada um fixava sua própria meta em função da quantidade ou qualidade das peças. Compreender essa função denota o lugar do trabalhador em constante troca simbólica, evidenciada na dinâmica entre circunscrever-se ao que os outros esperam dele e o que ele espera de si mesmo. Assim, "trabalhar coloca em tensão o uso de si requerido pelos outros e o uso de si consentido e comprometido por si mesmo" (Durrive \& Schwartz, 2008, p. 27).

Encarar sua tarefa não como expressão de uma demanda interna, mas como obrigação (facultada externamente, independentemente de ter caráter de voluntariado ou punição), fazia com que os trabalhadores se vissem como necessários, dando-lhes um senso de autovalor atrelado ao todo da atividade. A fala de Cássia exemplifica isso: “[...] é um jogo e eu me senti uma peça que eu ia ser usada naquele jogo, naquele momento, naquela hora. Acho que é a palavra mais certa de descrever é isso. Ele estava jogando, eu fui uma 
peça a ser escalada para aquele jogo e eu estou lá, enquanto precisar" (Entrevista de pesquisa, 2015).

Cássia expressa seu lugar de prestadora de serviço à comunidade, em uma função que, ao mesmo tempo, denotava uma possibilidade de ser útil e traduzia-se em experiência de resignação. Por conseguinte, nessa percepção ambígua do trabalho está presente não só o sentir-se agente, mas também, em vários momentos, o sentir-se objeto, isto é, o fato de os sujeitos participantes não se considerarem construtores cognitivos da ação. Lhuilier (2005, p. 211) aponta tal situação como "a valência dupla do trabalho, ao mesmo tempo espaço privilegiado de construção do sujeito e universo de constrangimentos e de exploração". O papel de meros executores ressalta nos discursos dos entrevistados por meio de expressões como "fui colocado", "fui mandado" e em uma alegada expectativa dos condutores do trabalho por uma adaptação inquestionável, por parte dos cumpridores, à posição que lhes era designada.

Por outro lado, os entrevistados frequentemente argumentaram que as facilidades encontradas pelo Ideias para a execução do trabalho não são comuns em outras instituições. Isso é sugerido, inclusive, por aqueles que nunca foram reencaminhados para outros lugares, caso da maioria dos sujeitos pesquisados. Também por isso, a pena não deixava de promover neles uma sensação de gratificação, sendo o trabalho executado compreendido como a base da penalidade.

Para além disso, percebiam como ganho o próprio sentido que atribuíam à atividade. A partir do caráter social do trabalho, admite-se que é por meio dele que se estabelecem as relações do indivíduo em sociedade, o qual se constrói nas trocas com seus pares, visto que estar em relação "oferece fora de si uma eventual realização de si na medida em que permite ao sujeito inscrever-se em uma história coletiva" (Barros \& Carreteiro, 2011, p. 214).

Segundo os cumpridores que fizeram parte desta pesquisa, produzir algo a ser utilizado para o bem de alguém os fortalecia e estimulava individualmente. Felipe relatou que havia encontrado um brinquedo na creche de seu filho, que provavelmente fora produzido pelo Ideias. Cássia, por sua vez, reafirma a função social do espaço e a contribuição de um trabalho de tal natureza em sua vida pessoal e na vida comunitária.

Então se faltam as estagiárias eu vou tomar conta das crianças. Cheguei ali com intuito de sair meio-dia e fiquei ali até 6 da noite. Você entendeu? Bom pra mim, bom pra ele [referindo-se ao coordenador da instituição], estava sozinho, não tinha quem estar ajudando e eu estava ajudando por realmente gostar de estar ajudando, eu não fui obrigada a fazer nada. Você sai de casa e fala "vou ficar lá 4 horas e vou pra casa", de repente você fica 10. Inclusive eu tenho ali na folha anotada 10 horas de trabalho. O tempo passa assim, voando. A gente nem percebe. Eu achei que valeu a pena. Eu achei que eu fiz uma boa escolha. (Entrevista de pesquisa, 2015)

Construir o sentido de sua atividade requer que o sujeito ressignifique sua identidade pela autovalorização, construída nas dinâmicas pulsionais e sociais. Segundo Lhuilier (2005, p. 
213), "o sentido não se prescreve, não se decreta. É sempre co-construído num duplo movimento de investimento de desejos inconscientes e de validações sociais". Todavia, é preciso compreender que a energia canalizada só pode ser sublimada quando existe um "'espaço transicional' que favorece a criatividade, o pensamento, a expressão livre e o desejo de construir" (Lhuilier, 2005, p. 213). Promover um "espaço transicional" para o cumprimento da pena depende da busca de uma maior coparticipação desses sujeitos na construção de suas atividades. $\mathrm{O}$ trabalho que não legitima o poder de agir (que não cria, não transforma) não possibilita movimento para a impressão da marca subjetiva na atividade (Clot, 2010). Daí a compreensão de que ter poder de agir é ter saúde, sendo isso o que permite ao trabalhador estabelecer sentido e eficiência a fim de dispor de si para aquilo que ele transforma em criatividade e afeto. Sem poder de agir, leva-se ao adoecimento (Clot, 2010).

No projeto "Cidadania dá em árvore?", algo experenciado como novo foi a possibilidade de reunir um número de trabalhadores em um único horário, em um único dia e em uma única atividade. Apesar de não haver nenhuma regra instituída que oriente sobre a quantidade de cumpridores ou horário de prestação de serviço, as instituições sociais, em sua maior parte, pedem para que o número seja reduzido, estabelecendo algumas orientações de horário para que não haja muitos sujeitos cumprindo a PSC ao mesmo tempo. Tal modelo de atuação é geralmente justificado pela baixa oferta de atividades na instituição ou pela crença de que, em grupos menores, os trabalhadores conseguem realizar atividades mais qualificadas.
Em entrevista, constatou-se como os cumpridores valorizavam os momentos compartilhados em grupo, apreciando sobretudo a conversa como estratégia de reflexão sobre os motivos de cada um estar em cumprimento de pena. As conversas realizadas nas oficinas transitavam por questões do cotidiano (violência no bairro, por exemplo) e experiências pessoais referentes aos motivos de condenação. Essa vivência coletiva permitia a cada um construir sua identidade pautada no reconhecimento mútuo. Assim, por meio da linguagem, era possível aos sujeitos afirmarem sua história, compreenderem a atividade que realizavam e a normalizarem (Lhuilier, 2005).

Nessa lógica, o espaço de compartilhamento ainda ressignificava o lugar da pena e da criminalização: os cumpridores falavam sobre suas relações com o Judiciário, com a Ceapa, com seus familiares e com seus trabalhos. Portanto, criavam-se novos laços e favorecia-se a narrativa individual, o que permitia uma troca de construções diárias que davam a conhecer o romance familiar (Gaulejac, 2009) do qual cada sujeito era produto.

Sobre o trabalho desempenhado pelos sujeitos, percebeu-se que o tempo era uma constante preocupação, uma vez que, apesar de a sentença ser dada em dias ou meses, o cumprimento era realizado em horas, na lógica de uma hora por dia (por exemplo: um ano equivale a 365 horas; 1 mês equivale a 30 horas). Essas horas eram fiscalizadas em uma folha de ponto, em que eram somadas e encaminhadas ao programa Ceapa, ao final de um mês. As horas eram a base para todo o cálculo e tinham, portanto, extrema importância para os 
cumpridores, afinal, fazer mais horas significava estar mais perto do fim da pena.

Gerir o tempo de forma a cumprir a obrigação judicial tornava-se uma tarefa complexa diante das outras tarefas dos sujeitos, como lazer, trabalho e família. Schwartz (2011) analisa o termo "gerir" no caso do trabalhador que se orienta em estratégias de administração de seu tempo, a partir das diversas dramáticas que cercam a execução da atividade. Percebeu-se que gerir a PSC era, essencialmente, deslocar o tempo que seria gasto para outras ações ligadas ao cotidiano dos cumpridores e redirecioná-lo para o cumprimento da pena. Assim, a obrigação se impunha como um compromisso semanal, que era integrado às diversas rotinas preexistentes.

Gerir a PSC, tradicionalmente, também era compreender que o tempo apresentado em juízo não necessariamente corresponderia ao tempo de cumprimento, podendo se estender dependendo da propensão do sujeito ao cumprimento. Graça, por exemplo, acelerou o cumprimento ao final - indo quase todos os dias da semana, de acordo com a disponibilidade do presidente para acompanhá-la -, apesar de ter demorado mais do que o estipulado. Em depoimento, diz querer cumprir sua pena para se mudar de estado, sendo a PSC a última "pendência" a ser resolvida para a concretização de seu intento. Já Atílio sugere que as horas eram um fator complicador porque não permitiam que tivesse momentos de lazer e que, apesar de estar no Ideias há mais de um ano, faltava muito tempo de serviço para encerrar os dois anos (ou 730 horas) que the haviam sido designados. Ele também aponta uma questão pertinente ao cumprimento da pena (igualmente vivenciada por Alexandre e Felipe): a necessidade de se ausentar durante o cumprimento da pena para trabalhar no "trecho", como é chamado o trabalho que se realiza por um espaço de tempo fora da cidade de origem.

Além das ausências dos sujeitos mencionados em virtude do "trecho", a PSC também foi irregular para Juliana, que, no tempo da pesquisa, compareceu poucas vezes, assim como outros prestadores, que são encaminhados e não comparecem. Nesses casos, o trabalho que seria cumprido com uma meta em folga fica prejudicado devido à não adesão dos sujeitos às atividades. Ao longo da observação, buscou-se uma resposta que viesse elucidar os motivos dessas faltas (tratadas pela Ceapa e pelo Judiciário como descumprimento); todavia, mediante a pluralidade subjetiva, fica claro que esses motivos também são plurais, entre os quais se destacam a não implicação com o trabalho, questões de saúde e trabalho e mesmo o descrédito que a falta acarretará alguma tipo de penalização.

Outro ponto levado em consideração diz respeito ao art. 46, inc. $3^{\circ}$, do Código Penal (1940): "As tarefas [...] serão atribuídas conforme aptidões do condenado." Oliveira (2009) questiona como as atividades estabelecidas para os cumpridores relacionam-se com suas aptidões, visto que muitos que poderiam exercer ações importantes, inclusive com formação adequada, são designados para atividades subalternizadas. Tais situações são vivenciadas com aborrecimento para alguns técnicos do programa Ceapa, capazes de perceber potencialidades nos sujeitos, postura que, em geral, não é reproduzida nas instituições devido ao discurso de desvalorização dos prestadores. $\mathrm{Na}$ pesquisa, quando perguntado sobre como era realizar a atividade para a qual foi direcionado, Felipe 
responde: "Pelo que eles fazem, eu acho importante, igual à questão de chamar pra pagar serviço comunitário, socar o cara pra cortar colonião, igual eu trabalhar de pedreiro o dia todo, ganho 100 ou 90 reais, aí eu vou prestar serviço e depois trabalhar o dia inteiro de pedreiro, não faz sentido [...]" (Entrevista de pesquisa, 2015)

Essa fala de Felipe mostra que, para ele, trabalhar como pedreiro também no contexto do cumprimento da pena seria uma atividade massacrante, em razão de ser esta uma função que lhe exige grande esforço físico. Nesse sentido, fortalecer a qualificação da PSC é mais do que fazer com que o ofício profissional do sujeito possa ser replicado no cumprimento da pena. Caso contrário, a PSC fortalecerá o discurso de dominação, submetendo os sujeitos a tarefas que repetem a subalternização da qual costumeiramente já são vítimas. Além disso, o trabalho marginal que muitos sujeitos realizam, trata-se muitas vezes do motivo direto ou indireto de estarem cumprindo PSC, como o caso de venda de produtos piratas, tráfico de drogas ou ainda crimes ambientais.

Durante as entrevistas, tornou-se evidente que o tratamento dado aos cumpridores durante a PSC é decisivo para a aceitação do cumprimento da pena. A entidade que exerce a ação de acolhimento é percebida como parte essencial para uma boa relação na instituição. Ser bem tratado é motivo para retornar e prosseguir na atividade, valorizando o trabalho: "precisam de mim, então estarei aqui para ajudar" (Entrevista de pesquisa, 2015).

Fica implícito na fala e no tom utilizado pelos entrevistados que a cordialidade que lhes é dirigida é recebida quase como um benefício, uma vez que, segundo entendem, a condição de cumpridores de pena poderia abrir margem para posturas discriminatórias que envolvessem rispidez e desprezo. Essa premissa não advém apenas do discurso social, ela é vivenciada na pele por muitos desses sujeitos, em razão da violência infligida pela polícia e até mesmo pelas penitenciárias, como no caso daqueles que ficaram presos ou cumpriram prisão provisória. Como não é difícil imaginar, o retrato do sistema penal por eles pintado é extremamente punitivo.

Ao final de cada entrevista, perguntou-se a cada sujeito como se sentiriam tendo cumprido a pena. De múltiplas formas, todos sugeriram o alívio de um fardo. Contudo, também houve os que afirmaram que provavelmente voltariam ao local de cumprimento da PSC, pois sentiriam falta da instituição e das interações em grupo.

Nesta pesquisa, percebeu-se que a pena não separa o sujeito da violência e do crime. A penalidade nunca será capaz de promover uma ação dessa natureza, sobretudo porque esse não é seu papel (Karam, 2010). Os espaços comunitários e suas atividades não retiram os sujeitos da situação de acentuada vulnerabilidade social, de maneira que ações punitivas ou mesmo educativas da PSC não dariam conta de resolver o problema da exclusão social.

Gomes (2009) salienta que a reincidência para penas alternativas se apresenta entre $2 \%$ e $12 \%$, sendo que pelo cumprimento no sistema prisional estaria em 85\%. Apesar do nível de reincidência para cumpridores de penas alternativas ser menor que o de sujeitos privados de liberdade, não é possível relacionar diretamente a não reincidência ao cumprimento de uma pena restritiva de direito. Observando os sujeitos que passaram pela instituição onde foi realizada esta pesquisa, percebe-se que a relação 
de alguns com o sistema penal foi algo bem pontual, já a de outros vem de longa data - muitos já havia passado pelo sistema prisional ou por caminhos de "inclusão às avessas" (Sawaia, 2010). Omar era um representante desse segundo grupo: jovem, negro, morador da área mais pobre do bairro, com baixa escolaridade e vinculado ao tráfico. Um dia chegou à instituição contando que talvez tivesse que cumprir outra pena, pois estava sendo acusado de ter tomado parte em um homicídio. Infelizmente, não chegou a ser julgado e nem pôde cumprir outro tipo de pena, pois foi baleado próximo à sua residência. Apesar de aparentemente justificar discursos proibicionistas, esse caso reafirma a necessidade de se repensarem as formas de lidar com a criminalização, pois a situação verificada nesses "campos de concentração a céu aberto" não tem permitido uma abordagem em que mortes, como a de Omar, possam ser evitadas.

\section{Considerações finais}

Esta pesquisa não teve como propósito formular uma construção inovadora sobre acompanhamento de cumpridores de PSC ou sobre como exercer uma atividade em regime de PSC. O que se buscou colocar em evidência foi a atividade desempenhada por pessoas que participaram da pesquisa. Longe de defender um formato que se arvore como o melhor para o cumprimento da PSC ou qualquer outra compreensão generalizante, buscou-se apenas problematizar sentidos vislumbrados durante o cumprimento da pena, que se afiguravam intrigantes naquele espaço.

Desde a criação da Cenapa, aponta-se a PSC como a estratégia mais valorativa de cumprimento de pena: órgãos de pesquisa contratados pelo $\mathrm{CNJ}$ demonstram que há uma preposição discursiva e prática para valorização dessa modalidade penal nos casos de penas alternativas (Ilanud, 2006; Ipea, 2014). Todavia, o que pode aparentar ser avanço pode ser, na verdade, repetição de um padrão já conhecido, pois, com uma possível banalização do emprego da PSC, pode-se resvalar para a mesma condição em que está hoje o sistema prisional: a de hipertrofia. Dessa forma, assim como os presídios estão lotados, as instituições sociais também podem ser sobrecarregadas com cumpridores de PSC.

Por fim, conclui-se que é tempo de pensar as políticas de segurança pública para além da repressão e das penas, sejam elas de prisão, sejam alternativas. Para isso, é necessário mais incentivo às práticas libertadoras, que se orientem pela participação social e pela valorização subjetiva. Práticas massificadoras ignoram o sujeito e seu poder de agir, por isso, impõe-se a necessidade de ouvir os trabalhadores, potencializando sua participação em prol de uma maior atuação nas atividades realizadas durante o cumprimento da pena.

\section{Referências}

Albernaz, E., \& Sá e Silva, F. C. M. (2009). Penas e medidas alternativas: uma utopia em construção. Brasília: Ministério da Justiça. Cadernos temáticos da CONSEG: segurança com cidadania nas penas e medidas alternativas, $3,12-15$.

Alves-Mazzotti, A. J. (2000). O método nas Ciências Sociais. In A. J. Alves-Mazzotti \& F. Gewandsznajder (Orgs.). O método nas 
ciências naturais e sociais: pesquisas quantitativas e qualitativas (pp. 109-203). São Paulo: Editora Pioneira.

Amado, G. (2005). Implicação. In J. Barus-Michel, E. Enriquez \& A. Levy (Orgs.). Dicionário de Psicossociologia (pp. 281-286). Lisboa: Climepsi Editores.

Antunes, R., \& Alves, G. (2004). As mutações no mundo do trabalho na era da mundialização do capital. Educação $e$ Sociedade, 25(87), 335-351. Recuperado em 3 agosto, 2017, de http:/ / www.redalyc.org/articulo.oa?id=87 314215003.

Augusto, A. (2010). Para além da prisão-prédio: as periferias como campos de concentração a céu aberto. In P. V. Abramovay \& V. M. Batista (Orgs.). Depois do grande encarceramento (pp. 175-182). Rio de Janeiro: Revan.

Barreto, F. (2006). Flagrantes e prisão provisória em casos de furto: da presunção de inocência à antecipação de pena. Dissertação de mestrado, Faculdade de Direito, Universidade de Brasília, Brasília.

Barros, V. A., \& Carreteiro, T. C. O. (2011). Clínicas do trabalho: contribuições da Psicossociologia no Brasil. In P. Bendassolli \& L. Soboll (Orgs.). Clínicas do trabalho: novas perspectivas para a compreensão do trabalho na atualidade (pp. 208-226). São Paulo: Atlas.

Bendassolli, P. F., \& Soboll, L. A. (2011). Clínicas do trabalho: novas perspectivas para a compreensão do trabalho na atualidade. São Paulo: Atlas.
Bitencourt, C. R. (1999). Novas penas alternativas: análise político-criminal das alterações da Lei $n$. 9714/98. São Paulo: Saraiva.

Braga, P. D. (1999). Os forçados das galés: percursos de um grupo marginalizado. In M. J. Barroca (Coord.). Carlos Alberto Ferreira de Almeida In Memoriam (187-200). Porto: Universidade do Porto, Faculdade de Letras.

Clot, Y. (2010). Trabalho e poder de agir. Belo Horizonte: Fabrefactum.

Correia Júnior, O. Z. (2016). "Eu, uma peça": o trabalho como pena alternativa. Dissertação de mestrado, Programa de Pós-graduação em Psicologia, Universidade Federal de Minas Gerais, Belo Horizonte.

Cunha, D. M. (2014). Ergologia e Psicossociologia do trabalho: desconforto intelectual, interseções conceituais e trabalho em comum. Cadernos de Psicologia Social do Trabalho, 17(spe), 55-64. Recuperado em 3 agosto, 2015, de http://pepsic.bvsalud.org/scielo.php?scri $\mathrm{pt}=$ sci_arttext\&pid $=\mathrm{S} 1516$ 37172014000100007.

Decreto-lei no 2.848, de 7 de dezembro de 1940. (1941). Código Penal. Recuperado em 03 de setembro, 2017, de http://www.planalto.gov.br/ccivil_03/dec reto-lei/Del2848compilado.htm.

Deleuze, G. (1992). Conversações (P. Pál Pelbart, Trad.). Rio de Janeiro: Editora 34.

Durrive, L., \& Schwartz, Y. (2008). Glossário da Ergologia. Laboreal, 4(1), 23-28.

Feyerabend, P. (2011). Contra o método (2a ed.). São Paulo: Editora Unesp. 
Foucault, M. (2009). Vigiar e punir (36a ed., R. Ramalhete, Trad.). Petrópolis: Vozes.

Goldenberg, M. (2009). A arte de pesquisar: como fažer pesquisa qualitativa em ciências sociais (11a ed.). Rio de Janeiro: Record.

Gaulejac, V. de (2009). O sujeito face à sua história: a démarche "romance familiar e trajetória social”. In N. M. Takeuti \& Niewiadomski, C. (Orgs.). Reinvenções do sujeito social: teorias e práticas biográficas (pp. XX-XX). Porto Alegre: Sulina.

Instituto de Pesquisa Econômica Aplicada (Ipea) (2015). A aplicação de penas e medidas alternativas (Relatório de pesquisa). Brasília: Ipea.

Instituto Latino-Americano das Nações Unidas para Prevenção e Tratamento do Delinquente (Ilanud) (2006). Levantamento nacional sobre execução de penas alternativas (Relatório final de pesquisa). Brasília: Ilanud.

Jinkings, I. (2013). Cárcere e trabalho: gênese e atualidade em suas inter-relações. In R. Antunes (Org.). Riqueza e miséria do trabalho no Brasil (Vol. II, pp. 75-92). São Paulo: Boitempo Editorial.

Karam, M. L. (2010). A violenta, danosa e dolorosa realização do poder punitivo: considerações sobre a pena. In V. Mattos (Org.). Desconstrução das práticas punitivas (pp. 11-26). Belo Horizonte: O Lutador.

Lhuilier, D. (2005). Trabalho. In J. Barus-Michel, E. Enriquez \& A. Lèvy. Dicionário de Psicossociologia (Vol. 1, pp. 210-220, M. R. P. Boléo, Trad.). Lisboa: Climepsi.

Lhuilier, D. (2009). Travail du négatif, travail sur le négatif. Education Permanente, 2(179), 3958.
Lhuilier, D. (2014). Introdução à Psicossociologia do trabalho. Cadernos de Psicologia Social do Trabalho, 17(spe), 5-20. Recuperado em 5 novembro, 2015 , de http://pepsic.bvsalud.org/scielo.php?scri pt=sci_arttext\&pid=S151637172014000100003 .

Lima, M. E. A. (2002). A questão do método em Psicologia do Trabalho. In I. B. Goulart. Psicologia organizacional e do trabalho: teoria, pesquisa e temas correlatos (pp. 123-132). São Paulo: Casa do Psicólogo.

Melossi, D., \& Pavarini, M. (2006). Cárcere e fábrica: as origens do sistema penitenciário (séculos XVIXIX) (S. Lamarão, Trad.). Rio de Janeiro: Revan/ICC.

Ministério da Justiça. (1998). Regras de Tóquio: comentários às regras minimas das nações unidas sobre as medidas não privativas de liberdade. Brasília: Ministério da Justiça.

Ministério da Justiça e Segurança Pública. (2017). Levantamento nacional de informações penitenciárias: Infopen Atualização - junho de 2016. Brasília: Ministério da Justiça e Segurança Pública. Departamento Penitenciário Nacional.

Neves, C. E. A. B. (1997). Sociedade de controle, o neoliberalismo e os efeitos de subjetivação. In A. do Eirado Silva et al. (Orgs.). Subjetividade: questões contemporâneas (pp. 84-91). São Paulo: Hucitec.

Oliveira, R. S. (2009). Em análise, a prática do psicólogo junto à pena de prestação de serviços à comunidade. Dissertação de mestrado, Programa de Pós-Graduação em Psicologia, Pontifícia Universidade Católica de Minas Gerais, Belo Horizonte. 
Paiva, I. L. D., \& Yamamoto, O. H. (2008). Os novos Quixotes da Psicologia e a prática social no "terceiro setor". Revista Psicologia Politica, 8(16), 231-250. Recuperado em 3 agosto, 2017, de http://pepsic.bvsalud.org/scielo.php?scri $\mathrm{pt}=$ sci_arttext\&pid $=\$ 1519$ -

549X2008000200004\&lng=pt\&tlng=pt.

Rabelo, L. D. B. C. (2014). Esse trem de fiscalização... O trabalho dos inspetores ferroviários em Minas Gerais. Dissertação de mestrado, Programa de Pós-Graduação em Psicologia, Universidade Federal de Minas Gerais, Belo Horizonte.

Rosenblatt, F. C. F. (2014). Um olhar crítico sobre o papel da comunidade nos processos restaurativos. Sistema Penal \& Violência, 6(1), 43-61.

Rusche, G., \& Kirchheimer, O. (2004). Punição e estrutura social (2a ed., G. Neder, Trad.). Rio de Janeiro: Revan.

Sawaia, B. et al. (2000). Introdução: exclusão ou inclusão perversa. In B. Sawaia (Org.). As artimanhas da exclusão: análise psicossocial e ética da desigualdade social (pp. 12). Petrópolis: Vozes.

Schwartz, Y. (2011). Manifesto por um ergoengajamento. In P. Bendassolli \& L. Sobbol (Orgs.). Clinicas do trabalho (pp. 132166). São Paulo: Editora Atlas.

Souza, G. A. D. D. (2014). "Punir menos, punir melhor": discursos sobre crime e punição na producão de alternativas à prisão no Brasil. Dissertação de mestrado, Programa de Pós-Graduação em Ciências Sociais, Pontifícia Universidade Católica do Rio Grande do Sul, Porto Alegre.
Trinquet, P. (2010). Trabalho e Educação. Revista HISTEDBR On-line, número especial, 93113.

Vasquez, A. S. (1977). Filosofia da Práxis (2a ed.). Rio de Janeiro: Paz e Terra.

Wacquant, L. (1999). Crime e castigo nos Estados Unidos: de Nixon a Clinton. Revista de Sociologia e Política, 13, 39-50. Recuperado em 3 agosto, 2017, de https://dx.doi.org/10.1590/S010444781999000200004.

Yamamoto, O. H. (2007). Políticas sociais, "terceiro setor" e "compromisso social": perspectivas e limites do trabalho do psicólogo. Psicologia \& Sociedade, 19(1), 3037. Recuperado em 3 agosto, 2017, de http://www.ufrgs.br/seerpsicsoc/ojs/vie warticle.php?id $=175$.

Zaffaroni, E. R. (2012). A palavra dos mortos: conferências de criminologia cautelar. São Paulo: Saraiva.

Recebido em: 5/3/2018 Aprovado em: 8/10/2018 